\title{
Nachruf für Prof. Dr. med. Franz Müller-Spahn
}

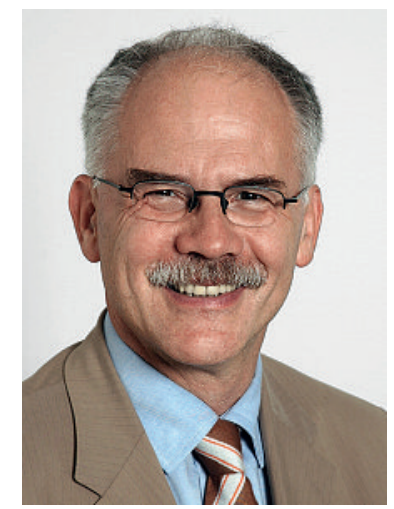

Prof. Dr. med.

Franz Müller-Spahn
Franz Müller-Spahn, Ärztlicher Direktor der Psychiatrischen Klinik und Ordinarius für Psychiatrie und Psychotherapie an der Universität Basel, starb am 4. August 2009 in seinem erst 59. Lebensjahr. Der frühe Tod des international prominenten psychiatrischen Wissenschaftlers und Arztes löste in den Fachgesellschaften der Schweiz und im Ausland tiefe Betroffenheit aus. Müller-Spahn hatte in seinem 15-jährigen Wirken an der Universität Basel wesentliche Impulse für eine Neuorientierung in der Psychiatrie und Psychotherapie gesetzt.

Franz Müller-Spahn war Bayer von Geburt, Mentalität und Passion. Er war Schüler von Hanns Hippius an der berühmten «Kraepelin»-Klinik, der Universitätsklinik für Psychiatrie an der Münchner Nussbaumstrasse, einem der einflussreichsten Zentren der deutschsprachigen Psychiatrie. Eine Institution, die sich stets in offener oder verdeckter Konkurrenz mit der «Bleuler»-Klinik, der Zürcher Psychiatrischen Universitätsklinik «Burghölzli», befand. Nach seiner Habilitation übernahm er eine Professur für Gerontopsychiatrie an der Universität Göttingen und kehrte später als Leitender Oberarzt an die Psychiatrische Klinik der Universität München zurück. 1994 wurde er zum Ärztlichen Direktor der Psychiatrischen Universitätsklinik in Basel und gleichzeitig zum Ordinarius für Psychiatrie und Psychotherapie an die Universität Basel berufen.

Auf der Basis einer fundierten klinischen, neurowissenschaftlichen und psychotherapeutischen Ausbildung interpretierte Franz Müller-Spahn die Psychiatrie als ganzheitliches, integratives Fach mit neurobiologischen, psychologischen, sozialen und philosophischen Aspekten. Der psychisch kranke und hilfsbedürftige Mensch stand für ihn stets im Mittelpunkt eines unermüdlichen Schaffens und hatte in seinem Tagesablauf höchste, persönliche Priorität. Er war einer der wenigen «Allround-Kliniker», der mit allen Subspezialitäten des Fachs Psychiatrie und Psychotherapie vertraut war, insbesondere der Schizophrenie, Depression, Suchtmedizin und Alterspsychiatrie. Unzählige Patienten und Angehörige verdanken ihm und seinen Mitarbeitern Besserung, Stabilisierung und Reintegration. Er verbesserte die Früherkennung psychischer Störungen mit sensitiven diagnostischen Instrumenten und stimulierte die Therapieforschung auf breiter Ebene, von der Psychopharmakologie, der Psychotherapie bis hin zur Sozialtherapie. Mithilfe seiner integrativen Fähigkeiten gelang es ihm, die zentrifugalen Kräfte der heutigen Subspezialisierungen zu bändigen und prominente Exponenten der Verhaltenstherapie, Neurowissenschaften, Stressforschung, Forensik und Rechtsmedizin bis hin zur Kinder- und Jugendpsychiatrie in die Universitäre Psychiatrische Klinik zu integrieren.

Die mitunter populäre und über weite Strecken unfruchtbare Debatte über den vermeintlichen Gegensatz zwischen der «Seele» auf der einen und der «Biologie» auf der anderen Seite befremdete ihn. Der Mensch in seiner individuellen Einzigartigkeit, ob gesund oder krank, war für ihn zu komplex und würdevoll für jegliche reduktionistische Polemik. In seiner Basler Zeit verfasste Franz Müller-Spahn unzählige wissenschaftliche Aufsätze und zahlreiche Bücher, darunter ein umfassendes Lehrbuch für Psychiatrie und Psychotherapie. Er profilierte sich, gesegnet mit einer genuinbrillanten Rhetorik, als einer der besten Dozierenden der Universität Basel und wurde dafür mehrfach ausgezeichnet. Das deutsche Bundesministerium berief ihn in zentrale Gutachtergremien und Beiräte zur Wissenschaftsförderung. Im Jahre 2002 wurde er in den Nationalen Forschungsrat des Schweizerischen Nationalfonds berufen, wo er bis zu seinem Tod das Fach Psychiatrie und Psychotherapie prominent und engagiert vertrat und damit einen wichtigen Beitrag für die Therapieforschung in seinem Fach leistete. Als Resultat seiner engagierten Nachwuchsförderung wurden mehrere bedeutende Lehrstühle der Psychiatrie und Psychotherapie sowie wichtige Chefarztpositionen von Psychiatrischen Kliniken mit Nachwuchskräften aus der Schweiz besetzt. Es war sein persönliches Anliegen, damit einen Beitrag an die Weiterentwicklung der Psychiatrie und Psychotherapie als humanes, ganzheitliches und integratives medizinisches Therapiegebiet zu leisten.

Neben seiner breit abgestützten fachlichen Expertise wird vor allem seine sympathische, geistreiche, herzliche Persönlichkeit fehlen, seine menschliche Wärme, seine loyale Kollegialität sowie sein bayerisch gefärbtes, humorvolles Wesen.

Prof. Dr. med. Christoph Hock, Universität Zürich

Dr. med. Hans Kurt, Präsident der Schweizerischen Gesellschaft für Psychiatrie und Psychotherapie 